\title{
REDLARA - Latin American Network of Assisted Reproduction
}

\author{
Ricardo Marques de Azambuja ${ }^{1}$
}

${ }^{1}$ Fertilitat Centro de Medicina Reprodutiva, Porto Alegre, Brazil

The Latin American Network of Assisted Reproduction (REDLARA) was founded in 1995 with 50 clinics from South America. The idea was to create a database for clinics that performed Assisted Reproduction in South America, where we could benchmark our performance vis-à-vis US (SART) or European clinics, and we could have our own data. The REDLARA developed very fast and in 1997, the Accreditation Program started. This program aims to standardize all the clinics participating in this Association and, therefore, enhance the data collected. It is very important to have minimal parameters that all the clinics should follow; enabling us to compare performance between regions and compare the clinical data with data from the same region where one operates, for instance. Another reason is to set a commitment to excellence, in which to be part of this association the clinic must have some minimal quality control and quality assurance processes. This will surely help improve our quality control parameters, and therefore your clinical results. Nowadays the association encompasses over 200 clinics and is still growing. Today there is an ethical committee, an educational committee and we are always trying to adapt to the very fast changes happening around us.

I was invited to participate in the Accreditation Committee in 2007 in Mar del Plata; and after 13 years participating in this committee, in 2020, I was invited to be the chairperson of this Committee, made up of eight professionals that work in different clinics, from different regions part of the REDLARA. Embryologists and physicians represent us. In the past, it used to be an embryologist and a physician, but because of the high cost, it was reduced to only one person - an embryologist, that is certified by
REDLARA, to visit clinics that are interested in participating in our association. Last year was an exception - we performed on line visits, meeting with the laboratory and medical directors. At this time, REDLARA also had two persons, an embryologist and a medical doctor.

Why should your clinic participate? REDLARA is, at least, a quality stamp, because not all clinics are part of it, and there is a minimal quality control and assurance that the clinic should follow. However for instance, if a clinic is interested in participating, and there are some issues that need to be addressed in this clinic, the accreditation committee can help with it. The committee can make suggestions, advise, visit the clinic and help solve problems and consequently improve your results.

In Brazil, almost $50 \%$ of the clinics are REDLARA members. Since our regulatory agency, ANVISA reviews many of the items that REDLARA reviews, it is feasible to have all data available to be evaluated and become part of REDLARA. In addition to having the committees and access to data, there are yearly regional meetings, and every other year there is the general meeting, where all Latin America participates, always featuring prominent speakers from all over the world.

Finally, I encourage you to be part of this association that is still growing, send your data, it is important to reassure that your data will always be confidential, and no other clinic will have access to you data, but you will always have access to the REDLARA overall data, as well as by region, and also by country.

If you are interested, visit our website (redlara.com) and get in touch with us. 